\title{
Lessons learned from the investigation of an anomalous termination of BETTII
}

Todd J. Veach, Stephen A. Rinehart, Dale J. Fixsen, Maxime J. Rizzo, Arnab Dhabal, et al.

Todd J. Veach, Stephen A. Rinehart, Dale J. Fixsen, Maxime J. Rizzo, Arnab Dhabal, Jordi Vila Hernandez de Lorenzo, Stephen Maher, Elmer Sharp, "Lessons learned from the investigation of an anomalous termination of BETTII," Proc. SPIE 10700, Ground-based and Airborne Telescopes VII, 1070028 (6 July 2018); doi: 10.1117/12.2313019

Event: SPIE Astronomical Telescopes + Instrumentation, 2018, Austin, Texas, United States 


\title{
Lessons learned from the investigation of an anomalous termination of BETTII
}

\author{
Todd J. Veach*a , Stephen A. Rinehart ${ }^{\mathrm{b}}$, Dale J. Fixsen ${ }^{\mathrm{b}}$, Maxime J. Rizzo ${ }^{\mathrm{b}}$, Arnab Dhabal ${ }^{\mathrm{b}}$, Jordi \\ Vila Hernadez de Lorenzo ${ }^{\mathrm{b}}$, Stephen Maher ${ }^{\mathrm{b}}$, Elmer Sharp ${ }^{\mathrm{b}}$ \\ ${ }^{\mathrm{a}}$ Southwest Research Institute, San Antonio, TX USA 78250; ${ }^{\mathrm{b}}$ Goddard Space Flight Center, \\ Greenbelt, MD USA 20771
}

\begin{abstract}
The Balloon Experimental Twin Telescope for Infrared Interferometry (BETTII) mission launched from Palestine, Texas in June 2017. After an exciting launch and successful cruise, the BETTII gondola suffered an anomalous event at termination. BETTII separated from its parachute and free-fell 136,000 feet into the west Texas desert. This event was classified as a "close-call" and investigated as such. We present here the recovery effort required to find the payload and extract the payload from its impact site. We also present lessons learned from the event and results from the investigation, the design for the next BETTII gondola, and a path forward for return to flight.
\end{abstract}

Keywords: Interferometry, Balloons, BETTII,

\section{INTRODUCTION}

The Balloon Experimental Twin Telescope for Infrared Interferometry (BETTII) is an eight-meter, fixed-baseline double-Fourier Michelson interferometer ${ }^{[1]}$ built to observe in the far infrared (FIR), from 35 to 90 microns at altitudes greater than 120000 feet. For a complete description of the BETTII payload, see Rinehart et al 2014.

BETTII was designed for multiple engineering and science flights over the course of several campaigns. The first engineering campaign was in the fall of 2016 in Fort Sumner, NM. However, due to poor weather, the one suitable launch attempt was scrubbed, and BETTII returned to GSFC. The second campaign, and eventually the first launch of the BETTII payload, occurred in the summer of 2017 in Palestine, TX. This was still an engineering campaign as BETTII was yet to fly. This is the campaign we will focus on here in this paper.

On June $8^{\text {th }}$ 2017, the BETTII payload launched from Palestine, Texas at approximately 7:30 PM central standard time. On June $9^{\text {th }}, 2017$, after a successful 12 hour engineering flight, BETTII had an anomalous termination event, leading to a free-fall from $\sim 130,000$ feet. This free-fall led to the almost complete destruction of the payload. In this paper, we will discuss the design decisions that led to the fall of BETTII, the pre- and post-flight analysis done by the BETTII team, the recovery of the BETTTII payload and the salvaged hardware, the analysis performed by Goddard Investigation Team, and the redesign of the critical component that failed in the original flight.

\section{OLD DESIGN}

\subsection{Control System Azimuth Pointing Design}

The payload control system and pointing requirements are described in great deal in Rizzo et al $(2014)^{[6]}$. Here we will focus on the azimuth control and the momentum dump as these two mechanisms tie most directly to the payload failure. The azimuth control of the payload is accomplished using two counter-rotating whiles spinning at a constant rate. This mechanism, known as the Compensated Control Moment Gyro (CCMG), provided the torque necessary to repoint the payload by changing the angles of the spinning wheels with respect to each other. As the angles are changed, momentum builds up in the payload that must by dumped using a momentum dump mechanism. The momentum dump mechanism uses a stepper motor to slowly dump momentum by de-rotating the BETTII payload. The BETTI de-rotator, or just rotator for the purposes of brevity, is a simple two-thrust bearing, flanged pin with enclosure design. This design allows for sub-arc second control of the payload while providing the mechanical attachment point to the balloon train, through a truck plate. 


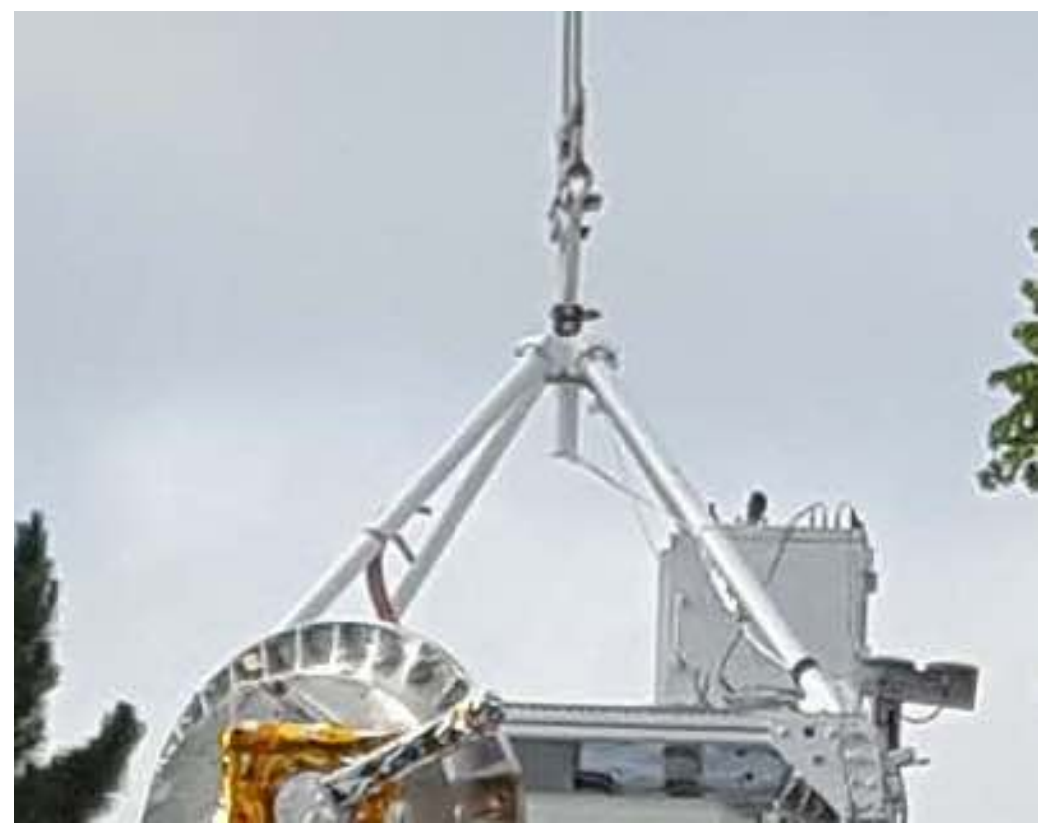

Figure 1 Shown here in action is the side view of the BETTII payload and it's attachment to the launch vehicle. At the top is the truck plate, followed by the rotator mechanism and the momentum dump motor.

\subsection{Mechanical Design}

A complete description of the mechanical design of BETTII is located in various papers ([1-6]). Here we will focus on the design of the BETTII rotator, the specific component that failed, and its associated subsystem.

The rotator is comprised of a shackle made of custom 455 steel, a pin made of the same material, a titanium housing, and two bearings for rotation. The bolt that attaches the pin to the shackle and the payload to the truck plate is a 0.5 -inch Grade 8 steel bolt. Both attachment bolts are loaded in double shear, minimizing the potential for catastrophic failure of the bolts.

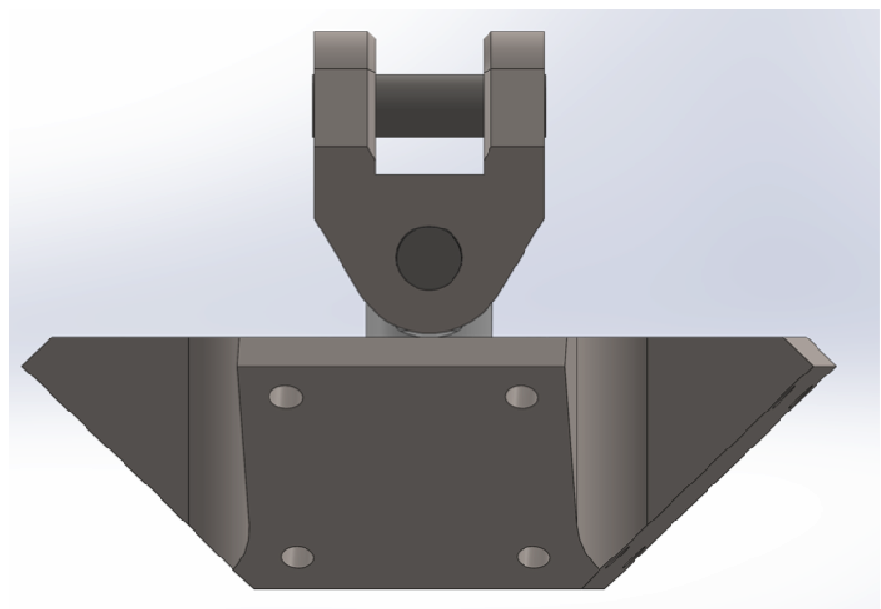

Figure 2 SolidWorks model of the rotator

In the cutaway view shown in Figure 4, we can see the rotator stackup. The pin is at the center of the model, with the two bearings supporting the titanium rotator housing. The pin OD is $24.50 \mathrm{~mm}$ and the flange OD is $42 \mathrm{~mm}$. The overall length of the pin is $68.00 \mathrm{~mm}$. The pin diameter is kept small to increase the control resolution of the payload and the pin 
length is kept short to minimize the inducement of lateral moments that would stress the pin. The hole in the pin for the mounting bolt has an ID of $12.95 \mathrm{~mm}$, perfectly sized for a 0.5 " bolt.

The rotator body was machined from Ti Al6-4V; a strong ductile material commonly used in aerospace and other high stress applications. The mass of the rotator body is $3.5 \mathrm{~kg}$. The opening in the rotator body is $25 \mathrm{~mm}$ allowing for a tight fit of the pin. This was again a decision made to minimize the non-axial loading of the pin and bearings. The neck of the rotator body is $9.53 \mathrm{~mm}$ thick. The housing dimensions are $152.4 \mathrm{~mm} \times 152.4 \mathrm{~mm} \times 50.8 \mathrm{~mm}$ with $67.5 \mathrm{~mm}$ hypotenuse isosceles triangles removed from the 4 corners for light weighting.

The bearings are from Lilly bearings and have a $25 \mathrm{~mm}$ ID and a $42 \mathrm{~mm}$ OD. One bearing uses ceramic balls and the other steel balls. The two bearing design was chosen to improve control of the payload. The bearings are operated without lubrication.

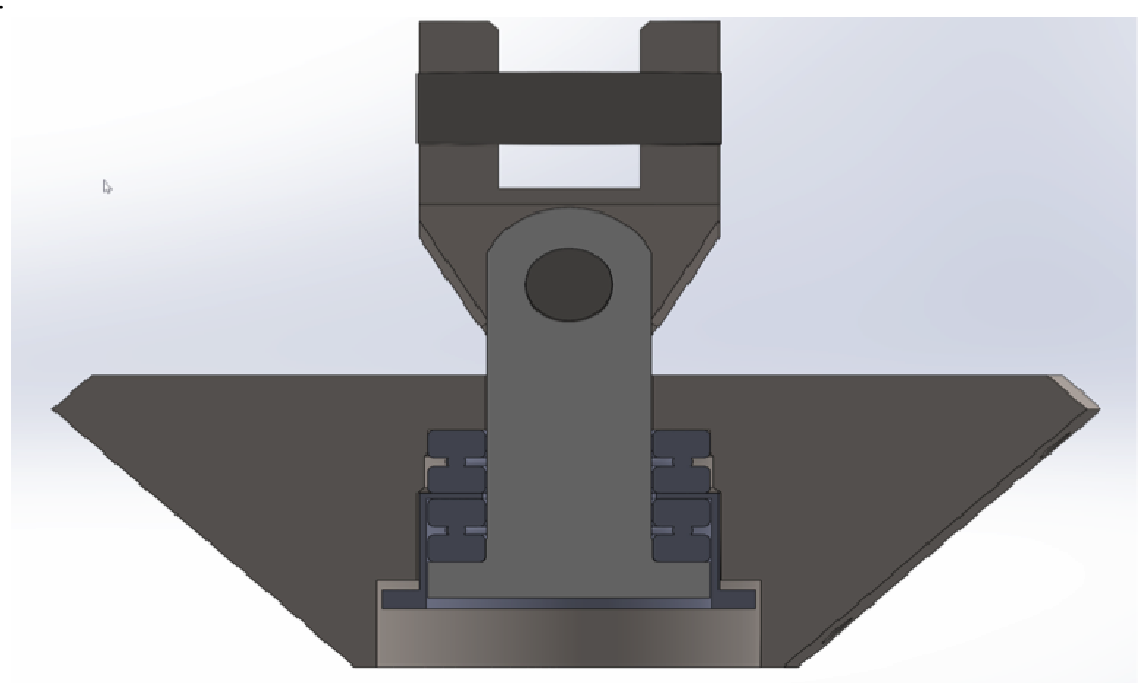

Figure 3 Cutaway of the SolidWorks model.

\subsection{Materials Selection}

The design of the BETTII rotator called out the following materials: Custom 455 steel, Al6061, aluminum nitride, stainless 405, and Ti6Al-4V. The rotator housing was fabricated from Ti6Al-4V, one bearing was ceramic, one bearing was stainless 405 , the bearing cup is aluminum, and the pin and shackle system were machined from custom 455 . Tables 1 and 2 provide the strength data for the Custom 455 and the Titanium.

Table 1: Strength Data for the Custom 455

\begin{tabular}{|l|c|}
\hline Custom 455, H900 & \\
\hline Tensile Strength, Ultimate & $1689 \mathrm{MPa}$ \\
\hline Tensile Strength, Yield & $1634 \mathrm{MPa}$ \\
\hline Elongation at Break & $11 \%$ \\
\hline
\end{tabular}

Table 2: Strength Data for the Ti 6Al-4V

\begin{tabular}{|l|c|}
\hline Ti 6Al-4V & \\
\hline Tensile Strength & $620 \mathrm{MPa}$ \\
\hline Tensile Strength, Ultimate & $950 \mathrm{MPa}$ \\
\hline Tensile Strength, Yield & $880 \mathrm{MPa}$ \\
\hline Elongation at Break & $14 \%$ \\
\hline
\end{tabular}


The Custom 455 was chosen as the pin and shackle material due to its extreme strength, machinability, and ability to be heat-treated. The BETTII team chose to heat-treat the pin in the H900 condition, which provides the highest strength achievable for this material. However, when treating the material to the H900 condition, the material has decreased ductility and decreased fracture resistance. Furthermore, the material can suffer from embrittlement when exposed to low temperatures for long periods of time.

\subsection{Finite Element Analysis}

According to the Columbia Scientific Balloon Facility (CSBF) Structural Requirements and Recommendations for Balloon Gondola Design document ${ }^{[8]}$, all load-carrying structural members, joints, connectors, decks, and suspension systems must be capable of withstanding, without ultimate failure:

1. A $10-\mathrm{g}$ vertical load at the suspension point.

2. A 5-g load applied at the suspension point and 45 degrees to the vertical.

3. A 5-g horizontal load.

Furthermore, critical components are recommended to have a ductility of greater than $10 \%$ and be able to withstand shock loading. If the ductility is lower than $10 \%$ or decreases to less than $10 \%$ as a result of embrittlement due to the extreme cold at float altitudes, the material should be considered brittle and a $50 \%$ load penalty should be used for analysis.

CSBF requires delivery of certifying documentation at least 60 days prior to the proposed launch date for review and approval. CSBF is ultimately responsible for the final approval of the critical components as they have the authority to deny launch if any component is deemed to fail safety analysis.

The finite element analysis of the original rotator pin was completed approximately five years before the BETTII flight. Analysis of the flight rotator pin was only completed as an assembly and this information was delivered to CSBF. In the analysis, it was shown that as a complete assembly, the rotator mechanism was designed to withstand a 10-g load for a payload weight of up to $2000 \mathrm{lbs}$. This analysis was provided to CSBF prior to launch and was certified by the CSBF payload engineer as acceptable for flight prior to the campaign in Fort Sumner. It was recertified for use just prior to the Palestine campaign the following year.

\section{PAYLOAD RECOVERY AND SALVAGE}

\subsection{Mishap}

After a successful 12-hour flight, the BETTII team decided to terminate the mission. After the termination command was sent at around 7:30 AM CST by the CSBF lead, the BETTII team followed the updates of the payload trajectory on the CSBF flight tracking webpage. The payload appeared to fall at a fairly quick rate, but other than that, everything seemed normal. The BETTII team prepared for recovery and travelled with the recovery team to the predicted landing site in West Texas, just northwest of San Angelo. However, en-route to recovery, we were informed that we would have to return to Palestine for a meeting. When we arrived in Palestine, it was then we were informed that there was an incident and the BETTII payload had detached from the parachute and free fell from float altitude, which was approximately 134,000 feet. 


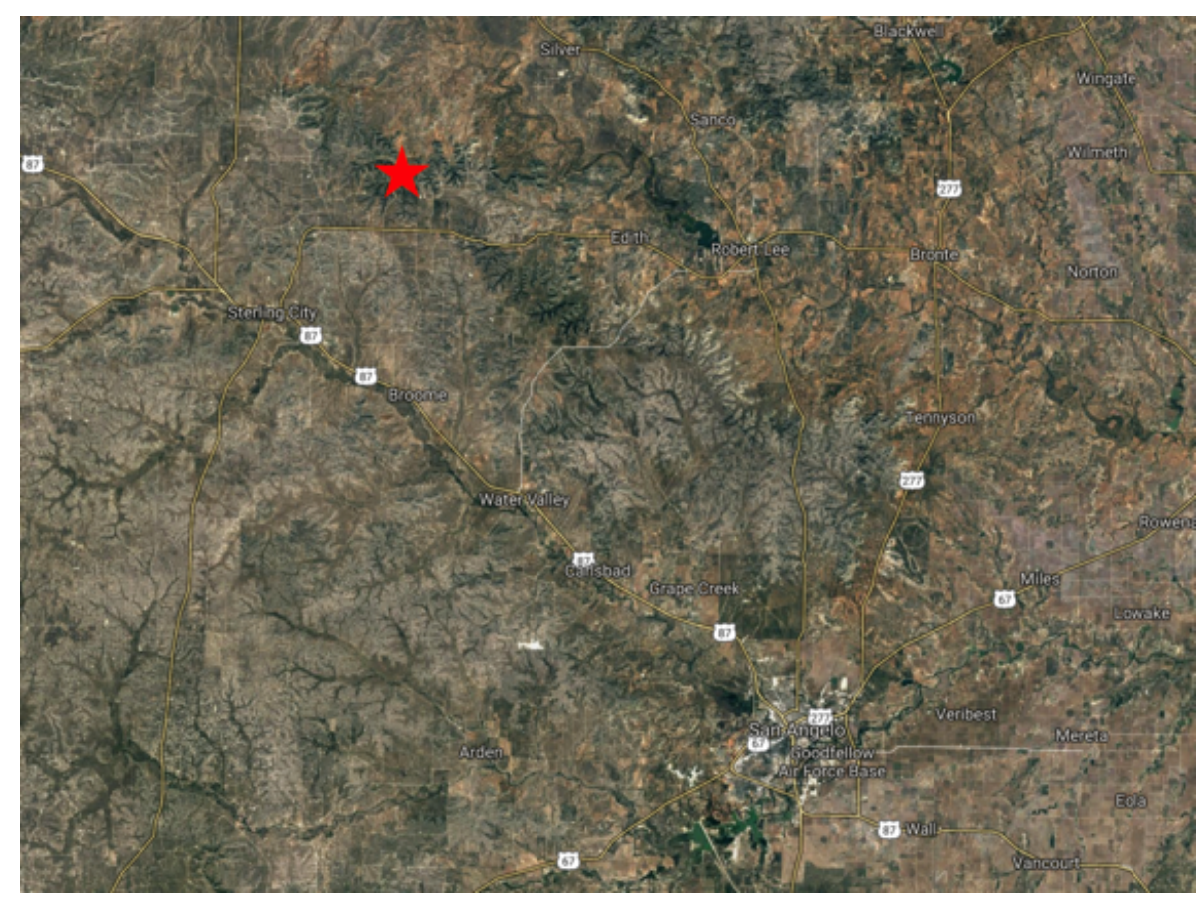

Figure 4: Approximate landing site of the BETTII payload.

\subsection{Recovery}

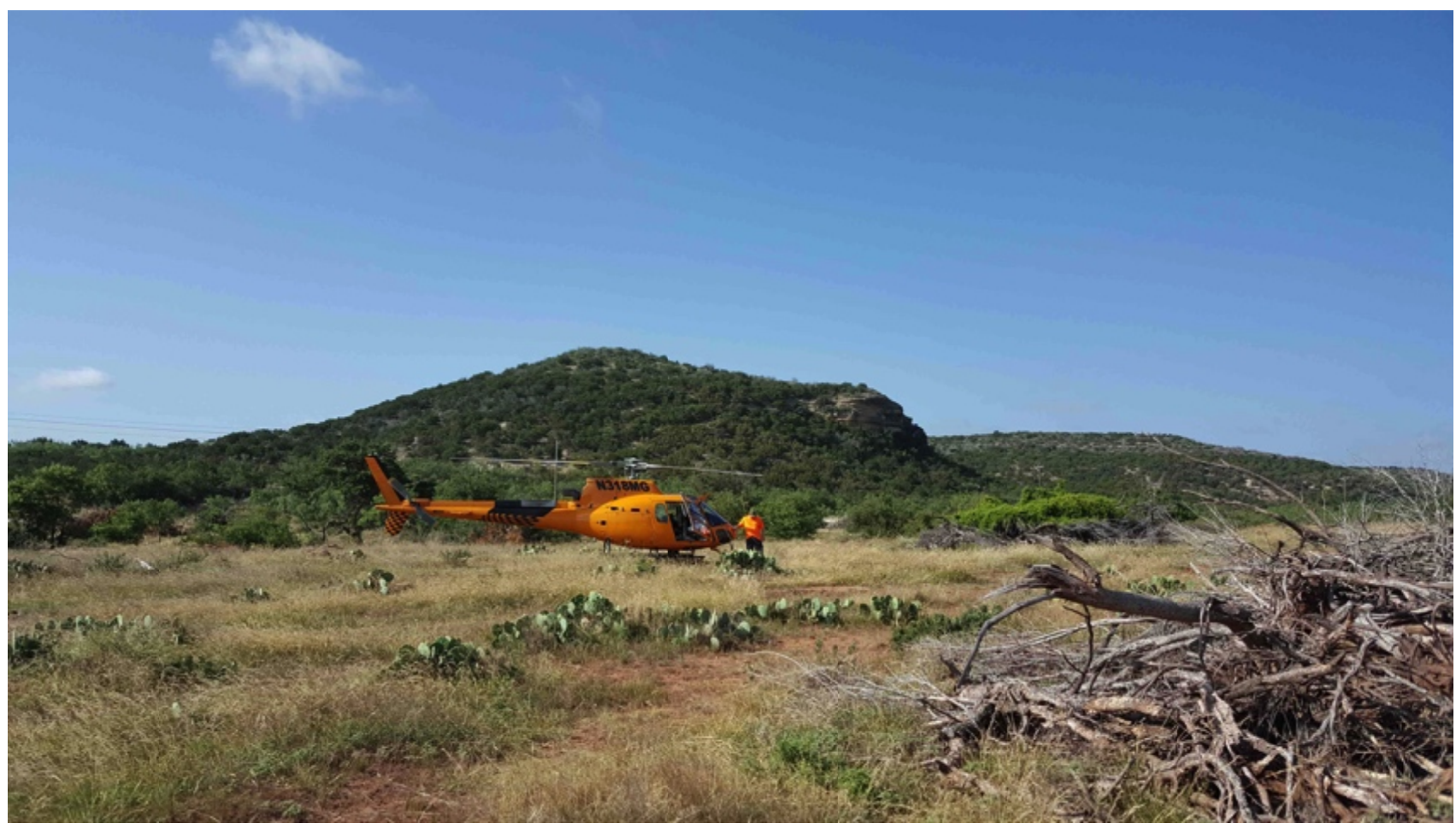

Figure 5 Helicopter Used for Recovery

The payload landed in a remote tree covered hill area about 90 miles northwest of San Angelo, as shown in Figure 4. Due to the remote nature of the landing site, extraction of the BETTII payload was completed via helicopter (Figure 5). Figures 6 shows the payload as it was resting when found at the recovery site. 


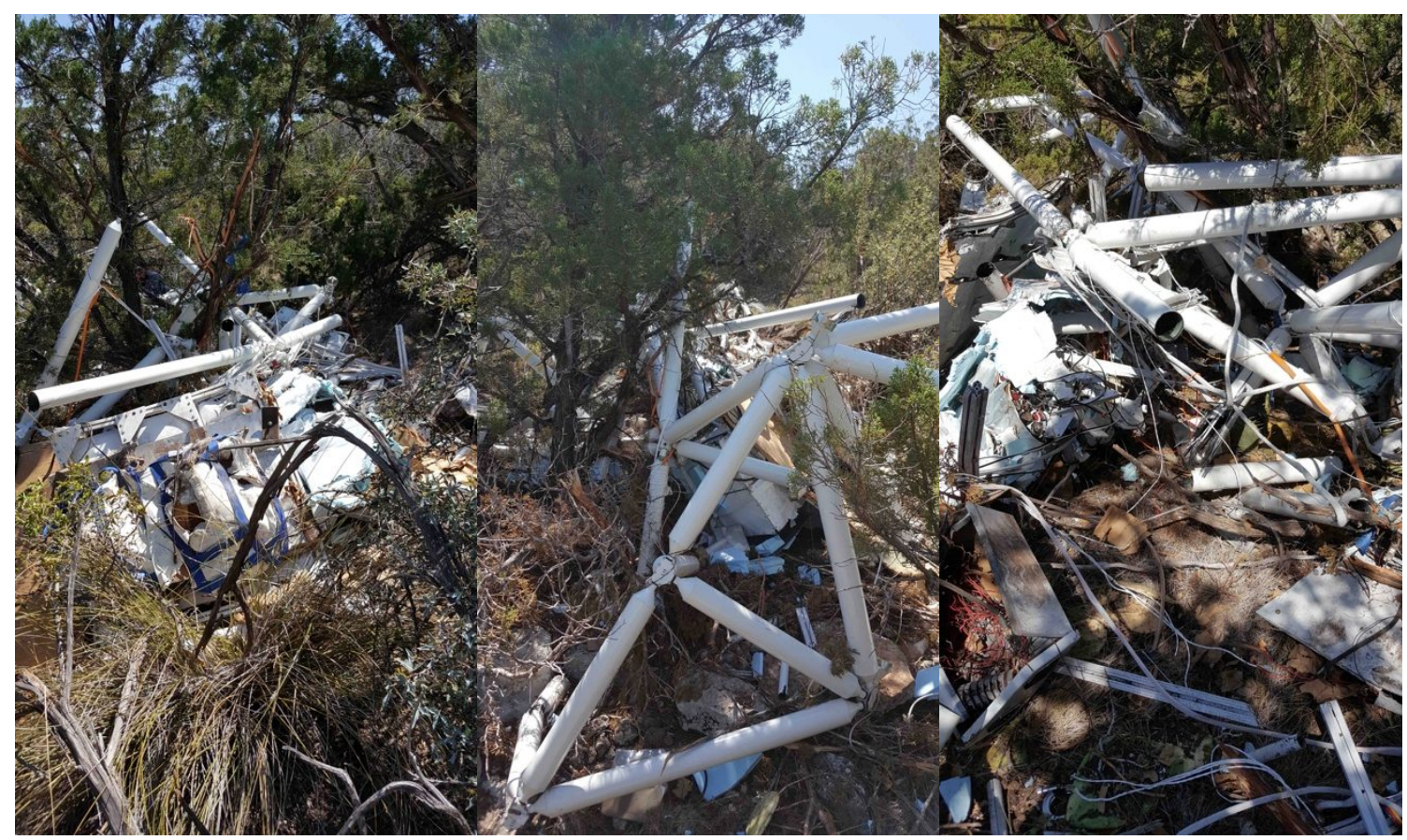

Figure 6 Three Views of the landing site of the BETTII Payload

As it can be imagined, coming upon this site was something to behold. From where we stood that day, it looked like the entire payload was destroyed. The primary goal was to ensure the integrity of the site for follow-up investigation; secondary goals were to salvage what could be recovered quickly and to protect any equipment with potential for reuse.

\subsection{Salvage}

On the day of recovery, we were actually able to a surprising amount of the payload. We were able to find all 11 flight data recorders (solid state hard-drives). Of the data recorders recovered, 9 of the 11 were $100 \%$ intact. The two drives that were unusable were the drives dedicated to the backup of the OS and had no flight science data on them. The others contained flight data in a triply redundant system. The drives had been mounted mechanically in an open frame, and one valuable lesson is that these SSDs are very resilient.

We were also able to recover all of the mirrors. When planning for nominal recovery, we had included a Pelican case in case any large optics needed to be removed from the payload. Having this case allowed us to pack all of the flight optics inside. More than $80 \%$ of the flight optics appeared to be useable with the naked eye. Further examination back at Goddard showed that one of the large mirrors was too deformed for reuse; the other three are potentially reusable, although additional testing is needed to verify this.

After the recovery operations, all of the recovered components, including everything that was highly damaged, were sequestered and stored in a warehouse in Palestine, TX. The BETTII team was not able to assess any further damage until after the initial investigation team deemed it acceptable, which happened about two months after the incident.

We returned to Palestine the weekend of July $23-26^{\text {th }}$. At this point we were able to assess the damage in a more detailed fashion and truly salvage anything that we might be able to use on the next BETTII flight. During this salvage operation, we were able to recover almost all of the detector readout electronics, some of the control electronics, the optics inside the cryostat as well as the external optics, and several other key components to the payload. From this recovery, we were able to ascertain approximately how much would need to be rebuilt and redesigned for the next BETTII flight. 


\section{POST-FLIGHT BETTII TEAM ANALYSIS}

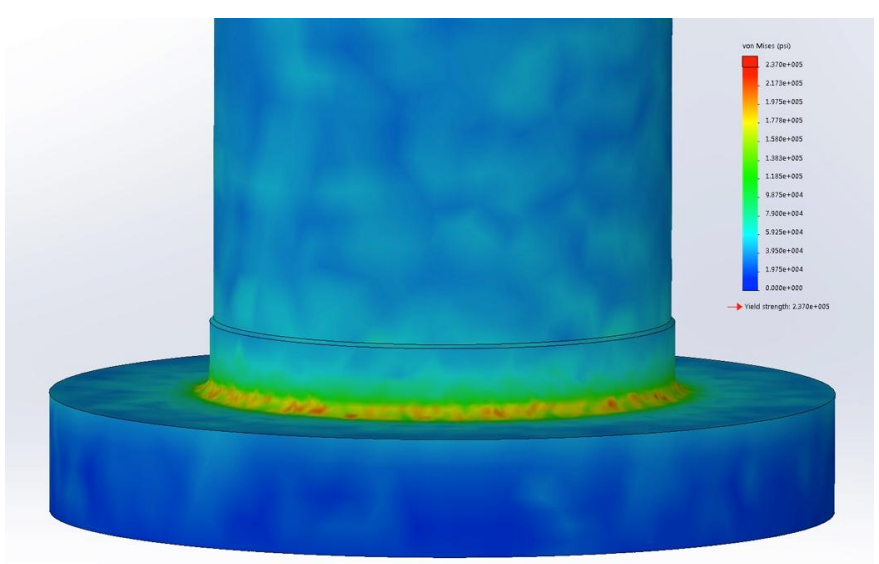

Figure 7 Re-Analysis Of Original BETTII Rotator Pin

\subsection{Post-Flight Analysis}

After the mishap, the BETTII team re-analyzed the original rotator pin since it appeared from the recovery that this was the component of the BETTII train that failed. As mentioned previously, it is standard protocol to assume that each individual component within the critical path in the suspension system must withstand the appropriate loads. Unfortunately, the engineer who carried out the initial design and analysis of the rotator had left the project several years previous and had not retained the detailed models that he had used for validation. Based upon part drawings, we were able to reconstruct the model and carry out a new analysis.

Upon re-analysis of the original pin design, the BETTII team found that the pin fractures at approximately $7.5 \mathrm{~g}$ of vertical loading (for a $2000 \mathrm{lbs}$ payload) after a 12 -hour cold soak at $230 \mathrm{~K}$. The pin was analyzed as a single part and not as part of an assembly for the re-analysis. From the re-analysis, it appears that the fracture was caused by an excessive stress concentration caused by the thin flange and sharp radius at the flange-pin interface as can be seen in figure 7 .

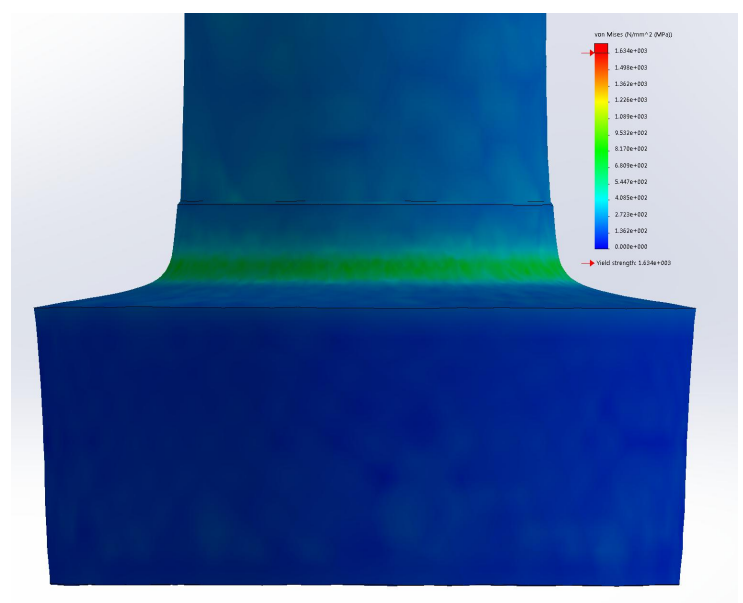

Figure 8 FEA capture of the final flange thickness required for a $2000 \mathrm{lbs}$ payload at $10 \mathrm{gs}$.

Additional contributing factors to the fracture of the flight pin were an embrittlement of the Custom 455 steel and slight non-uniform loading of the pin during the flight. The non-uniform loading of the pin created a stress concentration on 
only one side of the pin. After looking at photos of the flange and pin, the pin fractured at the point of this stress concentration first then propagated to the rest of the pin, causing catastrophic failure.

Ultimately, we determined that the largest contributing factor was the height of the flange. It was determined, through FEA analysis, that the .25 " thickness of the flange on the original pin should have been 0.75 ." A pin of 0.75 " would not have failed below 10-gs for a 2000-lbs payload, even with the sharp radius at the flange-pin interface (Figure 8).

\section{GODDARD ANALYSIS OF THE INCIDENT}

\subsection{Investigation and Cause Determination}

After the mishap, Goddard conducted an internal investigation to determine proximate causes, intermediate causes, contributing factors, and ultimately, the root cause. The proximate cause was determined to be the failure of the rotator pin. Two intermediate causes were also found:

1. The design of the rotator pin did not meet requirements.

2. The CSBF certifying engineer did not identify the design flaw prior to launch.

Additional contributing factors included the absence of a rip-stitch load-attenuation device on the balloon on which BETTII flew. For a rip-stitch to be effective, minimum mass of $3500 \mathrm{lbs}$ is needed. BETTII, as designed, weighed approximately $2200 \mathrm{lbs}$; ballast and crush pads increased the launch mass to nearly $3500 \mathrm{lbs}$, but nearly all of the ballast was dropped prior to BETTII's released. The root cause was determined to be a lack of sufficient communication of existing guidelines from CSBF to the BETTII team.

\section{REDESIGN}

\subsection{Mechanical Design}

Given the lessons learned from the analysis of the fall of BETTII, the team went back to the drawing board to redesign elements of the BETTII payload. The most important aspect of this redesign is to prevent another fall of BETTII, and thus a redesigned rotator has been a high priority. This new rotator design must still support the fine pointing control. This means that the design must simultaneously be large enough to survive required loads and small enough to provide sufficient payload control to achieve science goals.
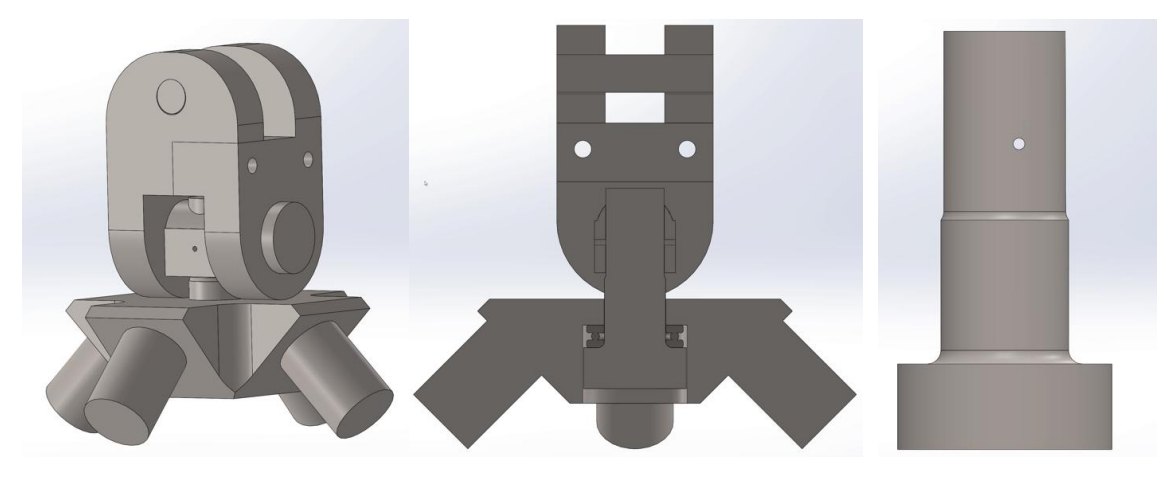

Figure 9 New Rotator Design. Not shown in the figures is the momentum dump motor and newly designed clutch system to provide uniform loading at all times on the pin.

The new rotator is much larger than the rotator from the first BETTII flight. The pin ID is $29.8 \mathrm{~mm}$, overall height is $98 \mathrm{~mm}$, and the flange height is $20 \mathrm{~mm}$. The shackle size and interface pin have also been increased significantly (by a factor of 1.75 from the original shackle design. The shackle is now also made from two pieces to accommodate the new interface of the pin to the cross-member. The top of the new rotator pin is threaded 1 1/8-28 UNF Class 3 fit. The inside 
of the cross member is obviously threaded accordingly. The two halves of the shackle are then held together by two 5/16-18 grade 8 steel bolts. The mass has also increased to $6 \mathrm{~kg}$. This rotator has been sized for a $3000 \mathrm{lbs}$ payload, which is currently a factor of 1.5 over the nominal weight of the new BETTII payload (2000 lbs). Furthermore, since the determined root cause from the investigation was a lack of communication of existing guidelines between CSBF and the BETTII team, we are now working with a CSBF-affiliated mechanical engineer to ensure the design is sufficient for flight.

\subsection{Materials Selection}

For the new rotator, we have chosen to build the entire rotator out of two grades of titanium. The plan for the shackle and pin is to use a special grade of titanium that is both strong and ductile. The material is Titanium variant Ti-6Al-2Sn-2Zr$2 \mathrm{Mo}-2 \mathrm{Cr}-25 \mathrm{Si}$. Table 3 presents the strength data of the titanium. It is easily seen that the strength values are lower than that of the Custom 455, but the ductility is almost a factor of 2 greater. The greater ductility, combined with the larger size of the rotator, allow for the new rotator design to survive for $10 \mathrm{~g}$ loading of a payload that is $3000 \mathrm{lbs}$.

Table 3 Strength Data

\begin{tabular}{|l|c|}
\hline Ti-6Al-2Sn-2Zr-2Mo-2Cr-.25Si & \\
\hline Tensile Strength, Ultimate & $1160 \mathrm{MPa}$ \\
\hline Tensile Strength, Yield & $1070 \mathrm{MPa}$ \\
\hline Elongation at Break & $18 \%$ \\
\hline
\end{tabular}

\subsection{Finite Element Analysis}

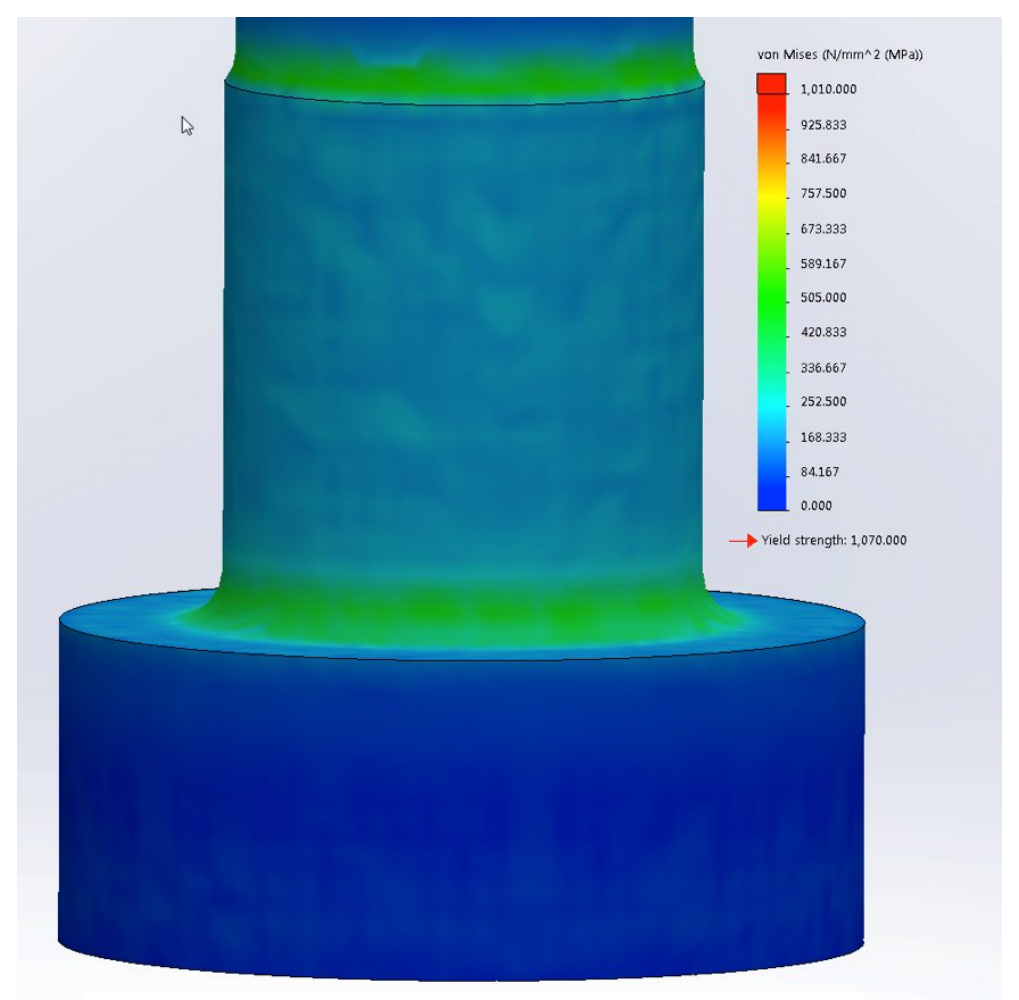

Figure 10 FEA of New Pin

Presented in Figure 9 is a capture of the finite element analysis for the new rotator pin. The loads applied are 10-gs for a $3000 \mathrm{lbs}$ payload and a cold soak temperature of $200 \mathrm{~K}$. This temperature correlates to the coldest temperature that the component will see on ascent. The highest value simulated on the pin is around 750MPA, which is a factor of 1.56 below the ultimate yield strength of the material. With this new design, maximum mass allowed meet requirements is $\sim 4500$ pounds. This is $2.25 \mathrm{x}$ the design weight of the new BETII payload. 


\subsection{Clutch System}

One of the lessons learned during the first BETTII flight relates to the loading of the rotator pin. From pictures and post flight analysis of the broken pin and broken bearings, it appears that during the flight, one side of the pin was under greater stress than the other side (Figure 10). It can be seen in Figure 10 that the pin has non-uniform discoloration indicative of asymmetric loading.

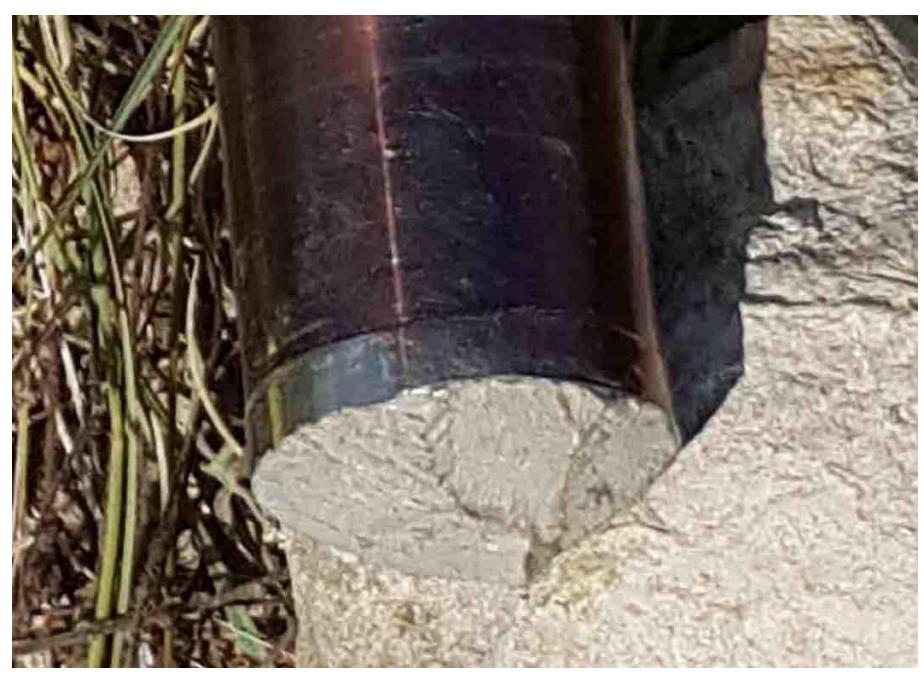

Figure 11 Non-uniform loading of the rotator pin.

The BETTII team designed a clutch system to provide for uniform loading of the pin at all times. The clutch is designed from standard aluminum 6061-T6 and a simple friction washer (Figure 11). The drive shaft on the clutch has 10 teeth to minimize loading on any one tooth and to maximize the control. The teeth can slide in and out of a mating shaft in order to apply uniform pressure to the base of the rotator pin. The gear shaft is keyed on the other end to slip over the drive shaft of the momentum dump motor. Pressure is maintained on the rotator via a spring and screw system not shown in the below figures.

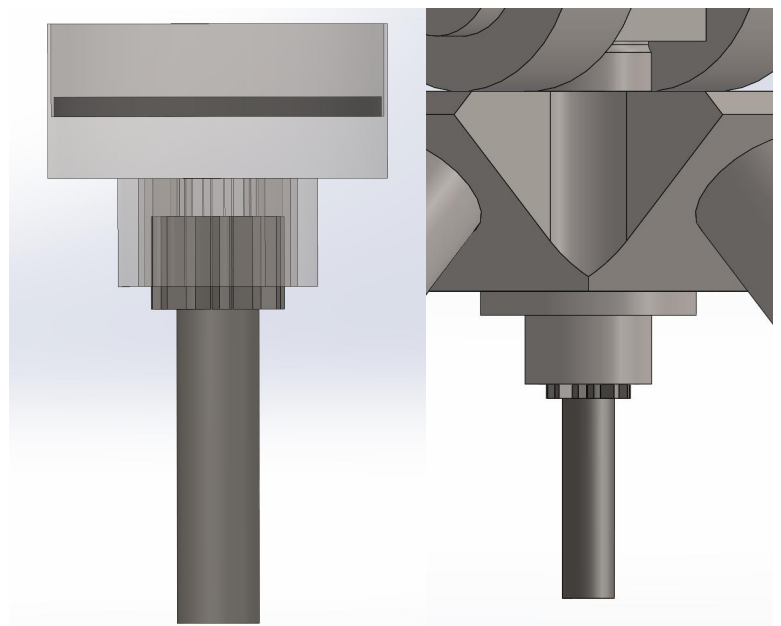

Figure 12 New system for applying uniform pressure to the rotator pin at all times to prevent asymmetric loading. 


\section{CONCLUSIONS}

Writing a conference proceeding about a failure is typically not something that is done. However, we felt is was important to convey to the community an internal assessment of what happened to the BETTII payload and hopefully provide some guidance as to the importance of good communication between instrument teams and the CSBF when designing and developing payloads. The BETTII team designed a pin that was insufficient to support the loading that was required by the CSBF for critical flight train components. Given the information that was provided, the CSBF certifying engineer approved the deficient design for flight on two separate occasions. Ultimately, the root cause of the

BETTII failure was a lack of effective communication between the groups involved in the process.

\section{REFERENCES}

[1]. Mariotti J. M. and Ridgway S. T. 1988 A\&A 195350

[2]. Rinehart, S., Maxime J. Rizzo, Dale J. Fixsen, Peter A. R. Ade, Richard B. Barclay, Richard K. Barry, Dominic J. Benford, Arnab Dhabal, Georgina Klemencic, Matthew J. Griffin, David T. Leisawitz, Stephen F. Maher, John E. Mentzell, Lee G. Mundy, Enzo Pascale, Robert F. Silverberg, Johannes G. Staguhn, Todd J. Veach, "The Balloon Experimental Twin Telescope for Infrared Interferometry (BETTII): An Experiment for High Angular Resolution in the Far-Infrared," Publications of the Astronomical Society of the Pacific, Volume 126, Issue 941, pp.660-673.

[3]. Rizzo, M., Stephen A. Rinehart, Dominic J. Benford, Dale J. Fixsen, Robert F. Silverberg, Todd J. Veach, "FarInfrared Double-Fourier Interferometers and their Spectral Sensitivity ," Publications of the Astronomical Society of the Pacific, Volume 127, pp. 1045-1060.

[4]. Rinehart, S., Maxime J. Rizzo, Dale J. Fixsen, Peter A. R. Ade, Richard B. Barclay, Richard K. Barry, Dominic J. Benford, Arnab Dhabal, Georgina Klemencic, Matthew J. Griffin, David T. Leisawitz, Stephen F. Maher, John E. Mentzell, Lee G. Mundy, Enzo Pascale, Robert F. Silverberg, Johannes G. Staguhn, Todd J. Veach, "The balloon experimental twin telescope for infrared interferometry (BETTII): interferometry at the edge of the atmosphere," Proc SPIE 9146-1, 2014.

[5]. Rizzo, M. ; S. A. Rinehart ; A. Dhabal ; P. Ade ; D. J. Benford ; D. J. Fixsen ; M. Griffin ; R. Juanola-Parramon ; D. T. Leisawitz ; S. F. Maher ; E. Mentzell ; L. G. Mundy ; A. Papageorgiou ; E. Pascale ; R. F. Silverberg ; G. Savini ; J. Staguhn ; T. J. Veach ; J. Vila Hernandez de Lorenzo; "The Balloon Experimental Twin Telescope for Infrared Interferometry (BETTII): towards the first flight." Proc. SPIE 9908, Ground-based and Airborne Instrumentation for Astronomy VI, 99080S (August 10, 2016); doi:10.1117/12.2231918.

[6]. Rizzo, M., Rinehart, S., Alcorn, J., Barclay, R., Barry, R., Benford, D., Dhabal, A., Fixsen, D., Gore, A., JohnsonShapoval, S., Leisawitz, D., Maher, S., Mundy, L., Papageorgio, A., Pascale, E., Rau, A., Silverberg, R., Taraschi, P., Veach, T., and Weinreich, S., "Building an Interferometer at the Edge of Space: Pointing and Phase Control System for BETTII", Proc. SPIE 9143, 3H (2014).

[7]. Veach, T.J.; Stephen A. Rinehart, John E. Mentzell, Dale J. Fixsen, Maxime J. Rizzo, Caitlin E. Gibbons, Dominic J. Benford, "The balloon experimental twin telescope for infrared interferometry (BETTII): optical design," Proc SPIE 9146-91, 2014.

[8]. https://www.csbf.nasa.gov/docs.html 